\title{
Stability and change in major life goals during the transition to parenthood alis
}

European Journal of Personality 2022, Vol. 36(I) 6I-7I (C) The Author(s) 2021 (c) (i) (5)

Article reuse guidelines: sagepub.com/journals-permissions DOI: $10.1177 / 0890207021996894$ journals.sagepub.com/home/ejop

(SAGE

\author{
Caroline Wehner' ${ }^{\prime}$, Manon A. van Scheppingen ${ }^{2}$ and \\ Wiebke Bleidorn ${ }^{3}$ (D)
}

\begin{abstract}
The transition to parenthood introduces changes in various life domains. In this paper, we examined whether and to what degree the transition to parenthood is related to changes in the importance of major life goals. To do this, we examined the rank-order stability, ipsative stability, and mean-level change in six life goal domains (achievement, power, variation, affiliation, altruism, and intimacy) in a sample of 248 parents and 294 individuals in a romantic relationship without children across two time points. Overall, we found high rank-order (variable-oriented) and ipsative (personoriented) stability, and little evidence for mean-level changes in the importance of life goals across the transition to parenthood. However, we found several selection effects suggesting that women without children tended to endorse agentic life goals (variation and achievement) more than mothers did. Generally, our findings underline the overall stability of life goals and their role as guiding principles in life.
\end{abstract}

\author{
Keywords \\ life goals, development, parenthood, period of transition, life event
}

Received I5 December 2020; Revised I5 December 2020; accepted 3 January 202 I

Major life goals reflect what people generally strive for in life (Roberts \& Robins, 2000). They provide guidance and consistency across situations (Hennecke \& Freund, 2017) and play a fundamental role in shaping people's everyday behavior. Several structural models of life goals have been suggested (e.g., Cantor et al., 1987; Pöhlmann \& Brunstein, 1997; Roberts \& Robins, 2000), most of which converge on the idea that goals can be hierarchically organized within two broad domains: agency (i.e., getting ahead) and communion (i.e., getting along; Bakan, 1966). Agentic goals include, for example, strivings for power, variation, or achievement; communal goals include strivings for intimacy, affiliation, or altruism (Pöhlmann \& Brunstein, 1997; Sheldon \& Cooper, 2008). Both agentic and communal life goals tend to be relatively stable over time (Bleidorn et al., 2010; Lüdtke et al., 2009; Roberts \& Robins, 2000). However, they are also dynamic concepts that can change over the life span and may change in response to environmental influences (Austin \& Vancouver, 1996) including major life events such as the transition to parenthood
(Bleidorn et al., 2010; Salmela-Aro et al., 2000, 2010).

In this study, we examine the rank-order stability, ipsative stability, and mean-level change in the importance of major life goals in the domains of agency and communion in a sample of first-time parents and a comparison group of romantic partners without children across two assessments over a period of one year. In doing so, we examined whether and which life goals predict parenthood status (selection effects) and whether new parents' life goals may change in response to the birth of their first child (socialization effects).

\footnotetext{
'Humboldt-Universität zu Berlin, Germany

${ }^{2}$ Tilburg University, The Netherlands

${ }^{3}$ University of California, Davis, CA, USA

Corresponding author:

Caroline Wehner, Psychological Assessment, Humboldt-Universität zu Berlin, Rudower Chaussee 18, 12489 Berlin, Germany.

Email:wehnerca@gmail.com
} 


\section{Stability and change in major life goals}

In the following, we provide a brief overview of different indices of stability and change (e.g., Caspi et al., 2005), review corresponding evidence for major life goals, and discuss possible mechanisms underlying stability and change in life goals.

Rank-order stability. Rank-order stability represents the extent to which the relative ordering of individuals on a certain variable remains stable across two assessment waves. The most straightforward way to assess the rank-order stability of a variable is a test-retest correlation.

Past research indicated that the rank-order stability of major life goals is moderate with average testretest correlations of $\sim r=.45-.60$ across periods of two to six years, with slightly lower stability estimates for younger (Hill et al., 2016; Lüdtke et al., 2009; Roberts et al., 2004) compared to older samples (Bleidorn et al., 2010; Bühler et al., 2019). More recent studies showed that life goals are also considerably rank-order stable over periods as long as 20 years (Atherton et al., 2020). Interestingly, previous studies suggested no discernible differences in the rank-order stabilities of life goals in samples with and without major life transitions, such the transition from school to college (Lüdtke et al., 2009). Indeed, life goals may act as guiding principles and promote consistency during periods of transition (Payne et al., 1991), such as the transition to parenthood. For example, importance of achievement-related goals could persist during the transition to parenthood, and just the time of attainment may be postponed.

Ipsative stability. In contrast to variable-oriented approaches such as rank-order stability, ipsative stability (also known as profile stability) is a personoriented indicator of stability vs. change. Ipsative stability describes the relative stability of the rankordering of constructs within an individual over time and has often been expressed as a $q$-correlation across two assessment waves (Ozer \& Gjerde, 1989; Stephenson, 1950). A high $q$-correlation, for instance, would indicate that a person who rated a certain life goal (e.g., achievement) as highly important relative to other goals at one time, continued to rate this life goal as highly important at a later assessment wave. In contrast, a low $q$-correlation would indicate changes in an individual's ratings of the relative importance of life goals over time. So far, only few studies have examined the ipsative stability of life goals with some indicating generally high ipsative stability of achievement goals (around .7; Fryer \& Elliot, 2007) and others indicating lower stability in social goals (around .4; Trucco et al., 2014).

Mean-level change. Mean-level change refers to average changes in a variable in a population and is often expressed as the standardized mean-level difference between two assessments over a certain period of time. Longitudinal studies found age-graded meanlevel decreases in the importance of most major life goals, particularly during young adulthood (Atherton et al., 2020; Hill et al., 2016; Lüdtke et al., 2009; Roberts et al., 2004; for an opposed finding, see Dunlop et al., 2017).

Mean-level decreases in goal importance have been theorized to reflect a normative age-graded decrease in social and personal resources. Such shifts in resources may limit the number of goals individuals can reasonably pursue at any given time (Lüdtke et al., 2009; Roberts et al., 2004). In other words, people likely adjust their goal priorities when faced with diminishing resources (e.g., Haase et al., 2013). For example, transitioning into work life and actively pursuing a career (strivings for power and achievement) may limit the amount of time an individual can invest in leisure activities or social relationships (strivings for affiliation) outside of their work context. Other goals such as living abroad (striving for variation) might be dropped entirely once a person pursues certain career goals. Thus, with a decrease in resources, the majority of goals may decrease in importance, while the importance of a few goals may remain stable or increase. Such a discerning approach to goal selection is thought to ensure higher levels of functioning and more effective goal pursuit (Baltes et al., 2006).

Summary. Different indices of stability and change can provide unique and non-overlapping information about the development of life goals. In the present study, we aim to provide a comprehensive examination of the rank-order stability, ipsative stability, and mean-level change in life goals during the transition to parenthood and in a comparison group of couples without children. In doing so, our main goal was to tease apart selection from socialization effects on life goals in the context of parenthood, as we will outline in more detail next.

\section{Life goals during the transition to parenthood}

Past research has established that major life goals can and do change across the lifespan with the most pronounced changes occurring during young adulthood (e.g., Hill et al., 2016). A natural question to consider is what drives these changes. Longitudinal behavioral genetic research has emphasized the influence of both genetic and environmental influences on change in major life goals (Bleidorn et al., 2010). However, the question remains what exactly is it in the environment that drives changes in life goals.

Major theories of aging and initial longitudinal evidence highlight the role of life events in goal development (Baltes \& Baltes, 1990; Brandtstädter \& Renner, 1990; Elder et al., 2003; Heckhausen, 1999; 
Pickles \& Rutter, 1991; Salmela-Aro et al., 2007). A life event that has been deemed particularly influential for young adults' development is the transition to parenthood. The transition to parenthood goes along with marked shifts in new parents' resources including their time (Craig \& Mullan, 2010; Nomaguchi \& Bianchi, 2004), finances (Nelson et al., 2014; Pollmann-Schult, 2014), mental health (Helbig et al., 2006; Mckenzie \& Carter, 2013), well-being (Nelson et al., 2014; Umberson et al., 2010), and interpersonal relationships (Bost et al., 2002; Doss et al., 2009). During pregnancy and early parenthood, resources such as time, energy, and money are likely oriented towards the child, leading to potential shortages in other areas of life. However, this effect might vary across parents depending on their resources and lifestyles prior to parenthood (see Roeters et al., 2016). For instance, people who used to spend a lot of time with their friends and social networks before childbirth may experience greater shifts in this particular domain compared to people who used to spend less time socializing.

Only few empirical studies have examined major life goals in periods of transition (e.g., Lüdtke et al., 2009). A key question for studies observing periods of transition is whether life goals predict the experience of life events (i.e., selection effects) or whether the experience of certain life events may shape people's life goals over time (i.e., socialization effects). For most parents in Western societies, the birth of a child is an event that is purposefully chosen and planned. Any associations between parenthood status and life goals may thus reflect both selection and socialization effects. Cross-sectional studies are useful in determining whether and to what degree parents differ in their life goals from nonparents. However, to disentangle selection from socialization effects, longitudinal studies including relevant comparison groups are needed.

For example, longitudinal research on parenthood and the Big Five provided robust evidence that higher levels of extraversion and lower levels of openness (Asselmann \& Specht, 2020; Jokela et al., 2011; van Scheppingen et al., 2016) predict selection into parenthood while there is little replicable evidence for socialization effects of parenthood on any of the Big Five traits (Denissen et al., 2019; Galdiolo \& Roskam, 2014; Specht et al., 2011; van Scheppingen et al., 2016). In contrast to the growing body of research on parenthood and personality traits, relatively little is known about selection effects of and socialization effects on major life goals. Indeed, to our knowledge, only one study has observed goal change during the transition to parenthood as of yet. Salmela-Aro et al. (2000) asked parents to list three personal goals, i.e. things they hoped to accomplish, which were then classified into one of 12 content categories by two assessors. Data were assessed three times, from 12 weeks pregnant to 3 months after birth. Providing initial evidence that certain life goals may change during the transition to parenthood, this study found decreases in self- and achievementrelated (i.e., agentic) goals and increases in family-related (i.e., communal) goals in mothers but not in fathers. However, little is known about changes in most lower-order goal domains. For example, intimacy and affiliation are both communal goals but may change differently during the transition to parenthood. While new parents may prioritize intimacy as a guiding principle in their lives, they may devalue the importance of affiliation goals, such as making new friends or socializing with others.

\section{The present study}

The purpose of this pre-registered (https://osf.io/ nb3qw/) study was to examine the rank-order stability, ipsative stability, and mean-level change in major life goals in a sample of expecting parents and a comparison sample of nonparents. Consistent with Austin and Vancouver (1996) and Pöhlmann and Brunstein (1997), we conceptualized major life goals as relatively broad guiding principles that, similar to values, define and structure major motives in life. In the assessment of life goals, researchers have distinguished individual differences in goal importance, attainability, progress, and effort (e.g., Pöhlmann et al., 2010). Here, we focus on the importance of life goals (see also Lüdtke et al., 2009; Roberts et al., 2004).

Although past research provided little evidence that life events impact the stability of broad individual difference variables (Specht et al., 2011), we first explored whether the rank-order (variable-oriented approach) or ipsative stability (person-oriented approach) of life goals is generally lower in parents compared to nonparents. We then examined selection and socialization effects for each of the six lowerorder goals summarized under the higher-order domains of agency (power, variation, and achievement) and communion (intimacy, affiliation, and altruism). Consistent with past evidence for changes prior to parenthood (e.g., Salmela-Aro et al., 2000), we expected to find significant mean-level differences between expecting parents' and nonparents' life goals even prior the transition to parenthood. Specifically, we predicted expecting parents to score lower in the agentic goal domains of variation and achievement and higher in the communal goal domains of intimacy and affiliation. Given the paucity of research on other goal domains, we refrained from specific predictions for power and altruism.

Based on past research on goal development, we predicted to find an overall decrease in the importance of life goals across parents and nonparents. With parents presumably experiencing a greater shortage in resources than nonparents, we expected them to show more pronounced mean-level decreases in variation, power, affiliation, and altruism than 
nonparents. Similarly, we expected more pronounced decreases in parents' compared to nonparents' agentic goals. Consistent with Salmela-Aro et al. (2000), however, we expected less pronounced or no decreases in parents' strivings for achievement and an increase in their strivings for intimacy. The mean-level change in communal goals was examined without a clear prediction. On the one hand we considered that the resource shortage might lead to a decline in the importance of communal goals, on the other hand the increase we predicted in intimacy might outweigh this decline.

Finally, based on previous findings highlighting the implications of parenthood for mothers' motives (Salmela-Aro et al., 2000), psychological well-being (e.g., Bleidorn et al., 2010), and resources (e.g., Baxter et al., 2015), we explored potential changes separately for mothers and fathers, and compared these to changes in women and men without children, respectively.

\section{Method}

\section{Participants and procedure}

We used data of first-time parents and couples without children from the Transition to Parenthood Study, a Dutch longitudinal study of participants with and without children. An overview of all variables assessed in this project can be found in the codebook which is publicly available at the projects' OSF page (https://osf.io/nb3qw/). All participants were in a romantic relationship and between 19 and 45 years old. Partners were invited to participate together but it was also allowed to participate without the romantic partner. A total of $N=542$ individuals participated at the first measurement occasion. The parent subsample consisted of 248 individuals (53.2\% female), of which 28 individuals participated without their partner. The majority of the parents were married or registered partners $(55.9 \%)$ or reported to live together $(43.3 \%)$. At the first measurement occasion, mothers $(n=132)$ were on average 29.15 years old $(S D=3.64$ years) and fathers $(n=116)$ were 31.13 years old $(S D=3.56$ years). Most pregnancies were planned $(92.4 \%)$. The nonparent subsample consisted of 294 individuals (51.4\% female), with 14 individuals who participated without their partner. Only a few couples were married or in a registered partnership (9.5\%), most couples lived together $(54.5 \%)$, and about onethird of the couples did not live together $(35.7 \%)$. Nonmothers $(n=151)$ had a mean age of 25.01 years $(S D=3.91$ years); nonfathers $(n=143)$ had a mean age of 27.43 years $(S D=4.86)$.

Participants completed online surveys at four measurement occasions. Here, we used data only data from the first ( 6 weeks before the expected birth date; later referred to as T1) and the third occasion (12 months after child birth; later referred to as T2), where the importance of life goals was assessed. The dataset has been used in past research (Lenhausen et al., 2021; Lenhausen et al., 2020; van Scheppingen et al., 2018). However, none of the studies focused on life goals and the first author of the present article had no access to the data prior to preregistering this study.

\section{Measures}

Agentic and communal life goals were assessed with a Dutch translation of the self-report GOALS questionnaire (Pöhlmann \& Brunstein, 1997; for more details, see Pöhlmann et al., 2010; Zimmermann et al., 2017). Participants rated the importance of three agentic goals: achievement (e.g., "I would like to continuously improve myself."), power (e.g., "I would like to be able to exert influence."), variation (e.g., "I would like to have adventures, live an adventurous life.") and three communal goals: intimacy (e.g., "I would like to give affection and love."), altruism (e.g., "I would like to help other people who are in need."), affiliation (e.g., "I would like to be friends with many people.") on four items each. All items were answered on a five-point rating scale ranging from 1 (completely not important) to 5 (very important). Internal consistencies at both time points were satisfactory $(\alpha=.74-.87, \omega=.69-96$; see Table S1 in the online supplement for details).

\section{Analyses}

All analyses were conducted using the software R ( R Core Team, 2020), and mainly the package lavaan (Rosseel, 2012). If not mentioned otherwise, analyses were conducted separately for agentic goals, communal goals, and the six lower-order goals. Across analyses, we compared mothers to nonmothers and fathers to nonfathers.

Rank-order stability. We assessed the relative ordering of the participants as a test-retest correlation across the two measurement occasions. We compared parents' and nonparents' correlations examining whether the correlations where outside of the confidence interval of the comparison group. For example, we tested whether the rank-order correlation for mothers' achievement fell within the $95 \%$ confidence interval of the rank-order correlation for nonmothers' achievement and vice versa.

Ipsative stability. We computed $q$-correlations between the six lower-order goals across measurement occasions for each individual. Correlations were Fisher's $z$-transformed, averaged and then back transformed to be able to compare individual changes between parent and nonparent groups. Again, we used confidence intervals to identify possible differences 
between groups. We used $F$-tests to compare variances between groups.

Selection and socialization effects. We used $t$-tests and report effect sizes to compare parents and nonparents prior to the transition to parenthood. Prior to testing socialization effects, we tested for measurement invariance across time, which is essential when change is assessed with latent models (Bollen \& Curran, 2006). Following the procedures described by Putnick and Bornstein (2016) we compared increasingly restrictive models: (1) configural: equal patterns of factors and factor loadings, (2) metric: equal factor loadings across time, and (3) scalar: equal factor loadings and equal item intercepts across time. We also tested for (4) partial scalar invariance: one or two item intercepts freed, when scalar invariance could not be established. We applied the criteria provided by Chen (2007), taking the less restrictive invariance level when the CFI increased more than .01 or the RMSEA decreased more than .015. We handled missing data using full information maximum likelihood (FIML) estimation.

Mean-level change was examined using latent change score models allowing residuals to correlate over time. Model fit was evaluated using standard recommendations for CFI (<.95), RMSEA $(<.06)$, and SRMR (<.08; Hu \& Bentler, 1999). Parceling was used for the models of agency and communion (Little et al., 2002; Little et al., 2013) with the respective lower-order goals as parcels; models for the six lower-order goals were estimated at the latent level using the respective items as indicators. We included age as covariate in the latent change score models. Finally, multiple group (Wald-) tests were used to compare the slope parameters from the latent change score models across the parent and nonparent samples.

\section{Results}

Prior to testing our hypotheses, we tested for potential effects of attrition by comparing participants who provided data at both assessments $(n=373)$ with those who dropped out at T2 $(n=169)$ with regard to age, gender, relationship length, and life goal scores assessed at T1. We found no significant differences in any of the demographic or life goal variables except for power with participants who remained in the study scoring lower in this domain $(M=2.88$, $S D=0.73)$ than those who dropped out $(M=3.06$, $S D=0.78), t(277.45)=2.41, p=.02$. Table 1 shows the means and standard deviations for each of the lower- and higher-order life goal domains for mothers, nonmothers, fathers, and nonfathers at T1 and T2.

\section{Rank-order stability}

Rank-order correlations were medium to large in size (see Table 2), ranging from $r=.47$ for intimacy in nonfathers to $r=.76$ for variation and affiliation in nonmothers. Significant differences, as indicated by values outside the comparison confidence intervals, emerged for variation between mothers $(r=.62)$ and nonmothers $(r=.76)$, and for achievement between fathers $(r=.50)$ and nonfathers $(r=.69)$. Similar trends indicating that parents were less stable than nonparents emerged for power and altruism. We found opposite trends for intimacy and variation which appeared to be more stable in fathers than nonfathers. In addition to these pre-registered tests, we

Table I. Mean level differences in goals across time for mothers, nonmothers, fathers, and nonfathers.

\begin{tabular}{|c|c|c|c|c|c|c|c|}
\hline \multirow[b]{2}{*}{ Goal } & & \multicolumn{2}{|l|}{ Females } & \multirow[b]{2}{*}{ Cohen's d } & \multicolumn{2}{|l|}{ Males } & \multirow[b]{2}{*}{ Cohen's $d$} \\
\hline & & TI M (SD) & $\mathrm{T} 2 \mathrm{M}(\mathrm{SD})$ & & TI M (SD) & $\mathrm{T} 2 \mathrm{M}(\mathrm{SD})$ & \\
\hline \multirow[t]{2}{*}{ Achievement } & Parents & $4.11(0.57)$ & $4.08(0.63)$ & -.06 & $4.16(0.52)$ & $4.07(0.53)$ & -.16 \\
\hline & Nonparents & $4.29(0.50)$ & $4.27(0.47)$ & -.06 & $4.26(0.58)$ & $4.06(0.54)$ & $-.34^{*}$ \\
\hline \multirow[t]{2}{*}{ Power } & Parents & $2.81(0.74)$ & $2.7 \mid(0.67)$ & -.14 & $3.03(0.69)$ & $2.97(0.70)$ & -.09 \\
\hline & Nonparents & $2.89(0.76)$ & $3.00(0.72)$ & .13 & $3.04(0.77)$ & $2.98(0.76)$ & -.07 \\
\hline \multirow[t]{2}{*}{ Variation } & Parents & $3.49(0.64)$ & $3.5 I(0.66)$ & .02 & $3.63(0.62)$ & $3.5 I(0.64)$ & -.18 \\
\hline & Nonparents & $3.73(0.74)$ & $3.7 \mid(0.65)$ & -.04 & $3.75(0.67)$ & $3.72(0.64)$ & -.06 \\
\hline \multirow{2}{*}{ Affiliation } & Parents & $3.45(0.74)$ & $3.58(0.78)$ & .18 & $3.47(0.77)$ & $3.42(0.76)$ & -.06 \\
\hline & Nonparents & $3.61(0.83)$ & $3.57(0.77)$ & -.06 & $3.52(0.77)$ & $3.39(0.73)$ & -.16 \\
\hline \multirow[t]{2}{*}{ Altruism } & Parents & $3.76(0.62)$ & $3.89(0.5 \mathrm{I})$ & .22 & $3.55(0.55)$ & $3.63(0.48)$ & .14 \\
\hline & Nonparents & $3.83(0.66)$ & $3.82(0.59)$ & -.01 & $3.50(0.66)$ & $3.39(0.67)$ & -.17 \\
\hline \multirow[t]{2}{*}{ Intimacy } & Parents & $4.59(0.42)$ & $4.62(0.42)$ & .07 & $4.26(0.5 \mathrm{I})$ & $4.25(0.54)$ & -.02 \\
\hline & Nonparents & $4.63(0.45)$ & $4.58(0.4 I)$ & -.10 & $4.34(0.48)$ & $4.28(0.46)$ & -.11 \\
\hline \multirow[t]{2}{*}{ Agency } & Parents & $3.47(0.50)$ & $3.43(0.5 \mathrm{I})$ & -.08 & $3.60(0.44)$ & $3.52(0.44)$ & -.20 \\
\hline & Nonparents & $3.64(0.50)$ & $3.66(0.48)$ & .03 & $3.68(0.48)$ & $3.59(0.51)$ & -.19 \\
\hline \multirow[t]{2}{*}{ Communion } & Parents & $3.93(0.45)$ & $4.03(0.4 I)$ & .22 & $3.76(0.46)$ & $3.77(0.46)$ & .01 \\
\hline & Nonparents & $4.02(0.5 I)$ & $3.99(0.43)$ & -.06 & $3.78(0.45)$ & $3.69(0.44)$ & -.22 \\
\hline
\end{tabular}

Note. TI: $n_{\text {mothers }}=132, n_{\text {nonmothers }}=149, n_{\text {fathers }}=96, n_{\text {nonfathers }}=134 ;$ T2: $n_{\text {mothers }}=96, n_{\text {nonmothers }}=107, n_{\text {fathers }}=73, n_{\text {nonfathers }}=97$. Cohen's $d$ coefficients above .20 are highlighted in bold. * $p<$.0 I. 
estimated multigroup structural equation models to test differences in the rank-order correlations while controlling for age. The results of these tests confirmed the aforementioned group differences and indicated an additional difference in the rank-order stability of fathers' and nonfathers' variation, with fathers showing higher stability. Detailed results of these additional analyses are presented in the supplemental materials (Table S2).

\section{Ipsative stability}

Overall, ipsative stabilities were high (all $r_{\mathrm{q}}>.85$ ) for both parents and nonparents. Results indicated no differences between mothers $\left(r_{\mathrm{q}}=.92,95 \%\right.$ CI [.88; .94]) and nonmothers $\left(r_{\mathrm{q}}=.92,95 \%\right.$ CI $\left.[.90 ; .94]\right)$, nor between fathers $\left(r_{\mathrm{q}}=.86,95 \%\right.$ CI $\left.[.79 ; .90]\right)$ and nonfathers $\left(r_{\mathrm{q}}=.86,95 \% \mathrm{CI}[.81 ; .90]\right)$. Furthermore, we found no differences in the variance of ipsative correlations among mothers and nonmothers $(F(93$, $105)=0.99, p=.96)$, and fathers and nonfathers $(F(54,91)=0.71, p=.19)$. We did not pre-register but explored differences between the ipsative

Table 2. Rank-order stabilities across TI and T2.

\begin{tabular}{lllll}
\hline & Mothers & Nonmothers & Fathers & Nonfathers \\
\hline Achievement & .63 & .61 & .50 & .69 \\
& {$[.48 ; .73]$} & {$[.47 ; .72]$} & {$[.29 ; .67]$} & {$[.57 ; .79]$} \\
Power & .59 & .64 & .59 & .64 \\
& {$[.44 ; .70]$} & {$[.51 ; .74]$} & {$[.39 ; .73]$} & {$[.50 ; .75]$} \\
Variation & .62 & .76 & .69 & .56 \\
& {$[.47 ; .73]$} & {$[.66 ; .83]$} & {$[.52 ; .80]$} & {$[.40 ; .68]$} \\
Affiliation & .71 & .76 & .74 & .73 \\
& {$[.59 ; .79]$} & {$[.67 ; .83]$} & {$[.60 ; .84]$} & {$[.61 ; .81]$} \\
Altruism & .58 & .67 & .58 & .66 \\
& {$[.43 ; .70]$} & {$[.55 ; .76]$} & {$[.38 ; .73]$} & {$[.52 ; .76]$} \\
Intimacy & .54 & .54 & .60 & .47 \\
& {$[.38 ; .67]$} & {$[.39 ; .66]$} & {$[.41 ; .74]$} & {$[.30 ; .62]$} \\
Agency & .58 & .72 & .69 & .68 \\
& {$[.43 ; .70]$} & {$[.62 ; .80]$} & {$[.53 ; .80]$} & {$[.55 ; .78]$} \\
Communion & .61 & .67 & .69 & .61 \\
& {$[.46 ; .72]$} & {$[.54 ; .76]$} & {$[.53 ; .80]$} & {$[.46 ; .72]$} \\
\hline
\end{tabular}

Note. Values in square brackets indicate $95 \%$ confidence intervals. stabilities of women $\left(r_{\mathrm{q}}=.92,95 \%\right.$ CI $\left.[.90 ; .93]\right)$ and men $\left(r_{\mathrm{q}}=.86,95 \%\right.$ CI $\left.[.82 ; .89]\right)$. The nonoverlapping confidence intervals indicate that on average men were less stable than women in their life goal profile, while they did not differ in variance $(F(200,148)=0.75, p=.06)$.

\section{Selection effects}

To test for selection effects, we compared the meanlevels of parents' and nonparents' life goals at T1 using $t$-tests (see Figure 1, and Table S3). Partly supporting our hypotheses for selection effects, we found several significant differences, particularly between mothers and nonmothers. Specifically, mothers rated achievement, $t(263.55)=2.87, p=.03, d=.35,95 \%$ CI [.11; $.58]$ and variation, $t(278.93)=2.92, p=.03, d=.35$, $95 \%$ CI $[.11 ; .58]$ as significantly less important than nonmothers did. Mothers also scored lower on the higher-order goal domain of agency, $t(274.90)=2.83$, $p=.04, d=.34,95 \%$ CI $[.10 ; .58]$, again as predicted. However, we found no support for the hypothesized differences in communal goals, and no evidence for differences between fathers and nonfathers in any of the lower- and higher-order goal domains.

\section{Socialization effects}

Prior to testing socialization effects, we conducted measurement invariance tests across assessments waves to make sure that mean-level differences of the latent variables can be compared across time. With one exception, results indicated scalar or partial scalar invariance for each of the six goals and the two higher-order goal variables (CFI >.95, RMSEA $<.07$, see Table S4 and S5 in the supplement). Specifically, for variation, change in RMSEA was .001 above the suggested threshold of .015 (Chen, 2007). However, the absolute fit of the scalar model was still excellent $(\mathrm{CFI}=.99$, RMSEA $=.02)$ suggesting that mean-level differences across assessment waves could be meaningfully interpreted.

The raw means indicated little change in both parent and nonparent samples from $\mathrm{T} 1$ to $\mathrm{T} 2$, with

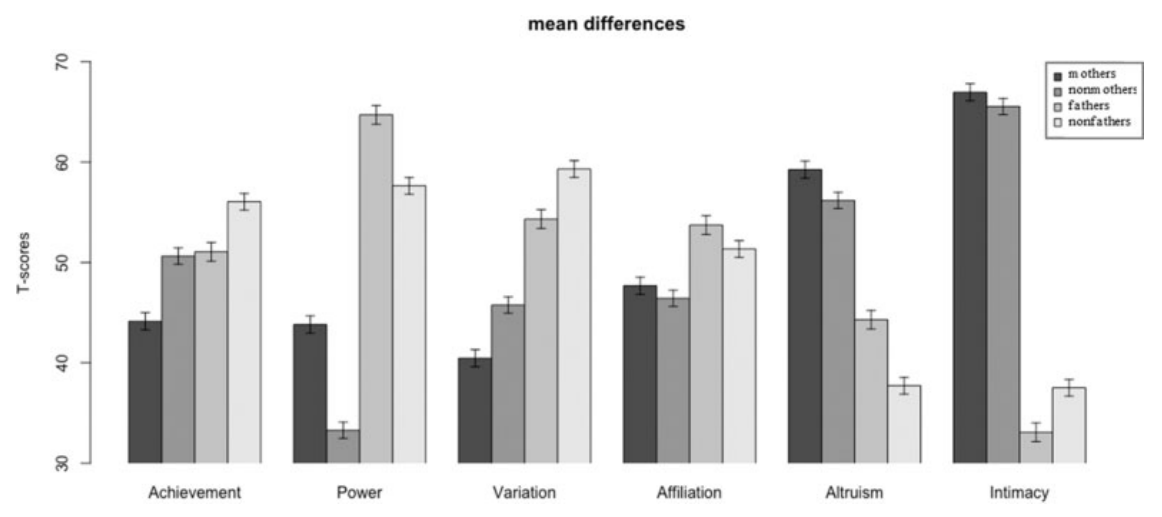

Figure I. Differences in goals between mothers, nonmothers, fathers, and nonfathers at TI. 
Table 3. Results of multigroup latent change models.

\begin{tabular}{|c|c|c|c|c|c|c|c|}
\hline \multirow[b]{2}{*}{ Goal } & & \multicolumn{2}{|c|}{ Parents } & \multicolumn{2}{|c|}{ Nonparents } & \multirow[b]{2}{*}{ Wald-test } & \multirow[b]{2}{*}{$p$-value } \\
\hline & & Slope & $p$-value & Slope & $p$-value & & \\
\hline \multirow[t]{2}{*}{ Achievement } & Females & .47 & .302 & .58 & .039 & 0.04 & .841 \\
\hline & Males & .10 & .856 & -.45 & .092 & 0.84 & .360 \\
\hline \multirow[t]{2}{*}{ Power } & Females & .49 & .185 & .32 & .259 & 0.13 & .741 \\
\hline & Males & .83 & .125 & -.15 & .606 & 2.53 & .112 \\
\hline \multirow[t]{2}{*}{ Variation } & Females & .32 & .591 & .04 & .915 & 0.16 & .687 \\
\hline & Males & -.01 & .993 & -.13 & .752 & 0.03 & .866 \\
\hline \multirow[t]{2}{*}{ Affiliation } & Females & .07 & .876 & .51 & .085 & 0.73 & .393 \\
\hline & Males & -.15 & .737 & -.01 & .982 & 0.08 & .783 \\
\hline \multirow[t]{2}{*}{ Altruism } & Females & .66 & .158 & -.02 & .956 & 1.38 & .241 \\
\hline & Males & -.58 & .247 & .17 & .622 & 1.52 & .218 \\
\hline \multirow[t]{2}{*}{ Intimacy } & Females & -.13 & .704 & .33 & .218 & 1.10 & .293 \\
\hline & Males & .83 & .135 & -.09 & .770 & 2.09 & .148 \\
\hline \multirow[t]{2}{*}{ Agency } & Females & .38 & .192 & .20 & .238 & 0.27 & .601 \\
\hline & Males & .11 & .727 & -.23 & .259 & 0.83 & .361 \\
\hline \multirow[t]{2}{*}{ Communion } & Females & .28 & .388 & .26 & .320 & 0.00 & .960 \\
\hline & Males & -.22 & .267 & .08 & .549 & 1.43 & .230 \\
\hline
\end{tabular}

Note. Females: Mothers are compared to nonmothers; Males: Fathers are compared to nonfathers. TI: $n_{\text {mothers }}=132, n_{\text {nonmothers }}=149, n_{\text {fathers }}=96$, $n_{\text {nonfathers }}=134 ;$ T2: $n_{\text {mothers }}=96, n_{\text {nonmothers }}=107, n_{\text {fathers }}=73, n_{\text {nonfathers }}=97$. Bolded values indicate a $p$-value $<.05$.

Cohen's $d$ ranging between .01 and .34 (goals $M_{\mathrm{d}}=.11$; see Table 1 ). Our results are very similar to previous findings, with effect sizes ranging from .02 to .33 across a study period of two years (Lüdtke et al., 2009). We found effect sizes above .2, which can be considered to be medium in size (Funder \& Ozer, 2019), for mothers, who tended to increase in altruism and communion, and nonfathers, who tended to decrease in achievement and communion.

We used multiple-group latent change score models to compare potential differences in mean-level trajectories in the six goals and the two higher-order goals between parents and nonparents. We chose to be less restrictive with the fit criteria and followed those already applied for other individual difference variables (Hopwood \& Donnellan, 2010) instead of those by $\mathrm{Hu}$ and Bentler (1999). With the exception of power $($ CFIs $<.90)$ all model fits were satisfying $(\mathrm{CFI}>.90$, RMSEA $<.09$, SRMR $<.11$, see Table S6 in the supplement). Table 3 shows the parameter estimates for the slopes of these models. We found only one significant slope, indicating a decrease of nonmothers in achievement. This was also the only slope on which the covariate age had a significant effect on ( $b=-.25, p=.030)$ indicating that older nonmothers decreased more in their endorsement of achievement goals. Using Wald-tests, we tested but found no differences between the slopes of mothers and nonmothers, and fathers and nonfathers.

\section{Discussion}

In the present study, we observed stability and change of life goals in first-time parents and couples without children. We examined stability using a variableoriented (rank-order stability) and a person-oriented approach (ipsative stability). Both indices indicated high stability in parents' and nonparents' life goals over the course of one year. Expecting mothers but not fathers differed from nonparents in several goal domains prior childbirth (selection effects). However, we found little evidence for mean-level change in general, or for differences in the mean-level change trajectories of parents and nonparents (socialization effects). Overall, these results suggest that the importance of major life goals is quite stable, even amid a major life event such as the transition to parenthood. As such, selection rather than socialization effects appear to explain the differences in life goals between parents and nonparents.

\section{How stable are life goals?}

The rank-order stability of all goal dimensions was high and in the range of previous findings (e.g., $r=.65-.75$ in Lüdtke et al., 2009). There were only few differences between parents and nonparents. Mothers appeared to be less rank-order stable than nonmothers in their endorsement of variation, and fathers appeared less stable than nonfathers in achievement. These results are consistent with our hypothesis of lower stability in parents. Notably, both variation and achievement are agentic goals which leads to the question why stability in parents tends to be lower in agentic but not in communal goals. One explanation may be that communal goals are generally more stable, which may express itself in transitional periods such as parenthood or in the long-term. Atherton et al. (2020) found some evidence that goals' stability tends to be higher in communal goals (family/relationship $r=.58$, social $r=.44$ ) than in agentic goals (economic $r=.36$; but political 
$r=.46)$ across 24 years. Overall, however, parenthood had a smaller effect on the rank-order stability of life goals than we expected given the profound impact parenthood entails on people's resources, life style, and routines. Notably, the limited sample size in each group resulted in relatively large confidence intervals which made their comparison a rather conservative test.

Not only the rank-ordering of individuals along the goal dimensions but also the rank-ordering of goal dimensions within individuals - the ipsative stability of life goals - was high in both parents and nonparents. That means, independent of the parenthood status for most individuals the order in the importance of their life goals did not change across the study period. However, we explored and found significant differences between women and men indicating that even though both genders were highly stable, men were slightly less consistent in the ranking of their life goals.

In summary, results for both indicators of stability, variable- and person-oriented, emphasized that life goals are rather stable constructs, even in the face of a major life event such as the transition to parenthood. This finding is consistent with the life goals literature that has highlighted their function as guiding principles that provide direction and consistency across situations and roles (Hennecke \& Freund, 2017; Roberts \& Robins, 2000).

However, high levels of rank-order and ipsative stability do not exclude the possibility of mean-level change in major life goals. To test whether life goals change during the transition to parenthood, we compared parents' and nonparents' life goals before and after the transition to parenthood.

\section{Do parents and nonparents differ in their life goals?}

As hypothesized, we found evidence for selection effects indicating that mothers and nonmothers differ in their life goals. Specifically, compared to nonmothers, mothers scored generally lower in the agency-related goals achievement and variation. This finding is consistent with our hypothesis that expecting mothers prioritize specific life goals. Indeed, the transition to parenthood might reflect certain goals, such as the idea to settle down, i.e. allows for less variation. The robust selection effect of low openness to experience (e.g., van Scheppingen et al., 2016), which is among others defined by a preference for variety and curiosity, is also in line with our finding of less variation in mothers. In qualitative interviews, Bass (2015) found that women tended to downshift their career goals, i.e. achievement, in anticipation of parenthood. Men, in comparison, usually did not do so, which is in line with our finding of no differences between fathers and nonfathers. This might be particularly pronounced in our Dutch sample, as the Netherlands have by far the highest rate of parttime employment in women compared to their neighboring countries (OECD, 2019) and a relatively short leave for fathers. We further hypothesized but found no selection effects for communal goals. As pointed out above, communal goals might be more stable than agentic goals (Atherton et al., 2020) and thus are less prone to change in general.

\section{Is parenthood associated with change in life goals?}

Previous research established age-graded mean-level decreases in life goal importance, particularly during young adulthood (Atherton et al., 2020; Roberts et al., 2004). This pattern might be a result of agegraded decreases in resources (Lüdtke et al., 2009; Roberts et al., 2004) that tend to occur as a consequence of life events such as the transition to parenthood. Goal selection, i.e. decrease in most life goals' importance, which is assumed to ensure functioning and effective goal pursuit (Baltes et al., 2006), may be accelerated by major life events. Consistent with these assumptions, we expected mean-level decreases in most life goals, particularly in parents, as they should experience an even greater decrease in resources than nonparents (see for example Nelson et al., 2014). Different to our expectations, we found very little evidence for mean-level change in life goals and only few differences between parents and nonparents.

In summary, we found little evidence for life goal change in response to the transition to parenthood. The lack of socialization effects associated with parenthood is consistent with research on other individual difference variables, such as the Big Five (Galdiolo \& Roskam, 2014; Jokela et al., 2011; van Scheppingen et al., 2016; but see also Asselmann \& Specht, 2020). Overall, life goals and other psychological variables appear to predict who will select into parenthood but do not seem to change in response to the experience of this life transition.

An important question is when the observed differences between parents and nonparents emerge. For example, parents-to-be may undergo changes in life goals long before their decision of having a child (see Bass, 2015) or during pregnancy. Salmela-Aro et al. (2000) found some evidence to support the hypothesis that parents' experience changes in life goals immediately before the birth of their child, at least with regard to mothers' achievement strivings. While the amount of achievement goals declined from the 12th to the 36th week of pregnancy in this study, it was stable from the 36 th week to 3 months after birth. In the present study, life goals were only assessed once before child birth, thus we could not quantify the timing of change.

\section{Gender differences}

We hypothesized that parenthood would have a more profound influence on mothers' than fathers' goal 
structures, as mothers experience generally more physical, emotional, and psychological changes and often assume the role of the primary caregiver (Poudevigne \& O'Connor, 2006; Ruppanner et al., 2019; Salmela-Aro et al., 2000). Even though we found only few effects, mothers tended to differ more in life goals from nonmothers, than fathers did from nonfathers. In particular, we found several selection effects in women's agentic life goals but none in men's. This might be explained by anticipation effects. That is, Bass (2015) found that women but not men tend to constrain their career aspirations in anticipation of potential future parenthood. She suggested that socially constructed gender expectations may be a driving force leading to more mental examination of possible role conflicts, time and financial constraints occurring with parenthood, which may ultimately lead to lower scores in agency related goals in becoming mothers. Gender differences may also be explained by selection, based on more stable individual differences in goals, instead of anticipation. For men who are high on agentic goals (in the Netherlands), it might not make a big difference for their career if they have children or not, as they just keep working. For women it does make a difference, so women high on agentic goals may be more likely to postpone childbirth or not have children at all.

\section{Limitations and future directions}

The strengths of this pre-registered study include the use of a prospective longitudinal design including parents and nonparents which allowed us to examine stability and change in life goals during the transition to parenthood. Nevertheless, there are several limitations that should be considered. First, even though the total sample consisted of more than 500 participants, the sample size within the groups of mothers, fathers, nonmothers, and nonfathers was only modest by contemporary standards resulting in limited statistical power. Second, studies with more and earlier assessments leading up to the decision of having a baby could provide important insights into potential anticipation effects prior and during pregnancy. With our data, we were not able to detect such potential early changes. Third, we found attrition effects for power indicating that participants who dropped out scored higher in this domain compared to participants who remained in the study. Moreover, the latent change score models for power did not fit the data well suggesting that the results for this goal domain should be interpreted with caution. Fourth, parents were on average about four years older than nonparents. These limitations emphasize the need for replication of our results in future research. Beyond that it would be interesting to not only look at goal importance but also into the effort people tend to put into reaching their goals. The interplay of goal importance and goal effort could help to further understand the development of life goals (see Atherton et al., 2020 for a similar reasoning).

\section{Conclusion}

We observed stability and change in life goals during the transition to parenthood to approach the question whether a major life event such as parenthood can be considered as an environmental influence that drives changes in life goals. We found selection effects indicating lower importance of agentic goals in mothers compared to nonmothers but little evidence that parenthood leads to change in major life goals.

\section{Data accessibility statement}

Al 2 The study materials, data and analysis scripts used for this article can be accessed at https://osf.io/nb3qw/.

\section{Declaration of conflicting interests}

The author(s) declared no potential conflicts of interest with respect to the research, authorship, and/or publication of this article.

\section{Funding}

The author(s) disclosed receipt of the following financial support for the research, authorship, and/or publication of this article: This study was funded by a grant to Wiebke Bleidorn by the Netherlands Organization for Scientific Research (Nederlandse Organisatie voor Wetenschappelijk Onderzoek, VENI project number 45113-025).

\section{ORCID iDs}

Caroline Wehner (D) https://orcid.org/0000-0001-9890-0733 Wiebke Bleidorn (D) https://orcid.org/0000-0003-3795-8143

\section{Supplemental material}

Supplemental material for this article is available online.

\section{References}

Asselmann, E., \& Specht, J. (2020). Testing the social investment principle around childbirth: Little evidence for personality maturation before and after becoming a parent. European Journal of Personality. https://doi.org/ 10.1002/per.2269

Atherton, O. E., Grijalva, E., Roberts, B. W., \& Robins, R. W. (2020). Stability and change in personality traits and major life goals from college to midlife. Personality and Social Psychology Bulletin. doi: 10.1177/ 0146167220949362

Austin, J. T., \& Vancouver, J. B. (1996). Goal constructs in psychology: Structure, process, and content. Psychological Bulletin, 120(3), 338-375.

Bakan, D. (1966). The duality of human existence: An essay on psychology and religion. Rand McNally.

Baltes, P. B., \& Baltes, M. M. (1990). Psychological perspectives on successful aging: The model of selective optimization with compensation. Successful Aging: Perspectives From the Behavioral Sciences, 1(1), 1-34. 
Baltes, P. B., Lindenberger, U., \& Staudinger, U. M. (2006). Life span theory in developmental psychology. In W. Damon \& M. Lerner (Eds.), Handbook of child psychology (pp. 569-664). Wiley.

Bass, B. C. (2015). Preparing for parenthood? Gender, aspirations, and the reproduction of labor market inequality. Gender \& Society, 29(3), 362-385.

Baxter, J., Buchler, S., Perales, F., \& Western, M. (2015). A life-changing event: First births and men's and women's attitudes to mothering and gender divisions of labor. Social Forces, 93(3), 989-1014.

Bleidorn, W., Kandler, C., Hülsheger, U. R., Riemann, R., Angleitner, A., \& Spinath, F. M. (2010). Nature and nurture of the interplay between personality traits and major life goals. Journal of Personality and Social Psychology, 99(2), 366-379.

Bollen, K. A., \& Curran, P. J. (2006). Latent curve models: A structural equation perspective. John Wiley \& Sons.

Bost, K. K., Cox, M. J., Burchinal, M. R., \& Payne, C. (2002). Structural and supportive changes in couples' family and friendship networks across the transition to parenthood. Journal of Marriage and Family, 64(2), 517-531. https://doi.org/10.1111/j.1741-3737.2002. 00517.x

Brandtstädter, J., \& Renner, G. (1990). Tenacious goal pursuit and flexible goal adjustment: Explication and agerelated analysis of assimilative and accommodative strategies of coping. Psychology and Aging, 5(1), 58-67.

Bühler, J. L., Weidmann, R., Nikitin, J., \& Grob, A. (2019). A closer look at life goals across adulthood: Applying a developmental perspective to content, dynamics, and outcomes of goal importance and goal attainability. European Journal of Personality, 33(3), 359-384.

Cantor, N., Norem, J. K., Niedenthal, P. M., Langston, C. A., \& Brower, A. M. (1987). Life tasks, self-concept ideals, and cognitive strategies in a life transition. Journal of Personality and Social Psychology, 53(6), 1178-1191.

Caspi, A., Roberts, B. W., \& Shiner, R. L. (2005). Personality development: Stability and change. Annual Review of Psychology, 56, 453-484.

Chen, F. F. (2007). Sensitivity of goodness of fit indexes to lack of measurement invariance. Structural Equation Modeling, 14(3), 464-504.

Craig, L., \& Mullan, K. (2010). Parenthood, gender and work-family time in the United States, Australia, Italy, France, and Denmark. Journal of Marriage and Family, 72(5), 1344-1361.

Denissen, J. J., Luhmann, M., Chung, J. M., \& Bleidorn, W. (2019). Transactions between life events and personality traits across the adult lifespan. Journal of Personality and Social Psychology, 116(4), 612-633.

Doss, B. D., Rhoades, G. K., Stanley, S. M., \& Markman, H. J. (2009). The effect of the transition to parenthood on relationship quality: an 8-year prospective study. Journal of Personality and Social Psychology, 96(3), 601-619.

Dunlop, W. L., Bannon, B. L., \& McAdams, D. P. (2017). Studying the motivated agent through time: Personal goal development during the adult life span. Journal of Personality, 85(2), 207-219.

Elder, G. H., Johnson, M. K., \& Crosnoe, R. (2003). The emergence and development of life course theory. In J. T. Mortimer \& M. J. Shanahan (Eds.), Handbook of the Life Course (pp. 3-19). Springer US. https://doi.org/ 10.1007/978-0-306-48247-2_1

Fryer, J. W., \& Elliot, A. J. (2007). Stability and change in achievement goals. Journal of Educational Psychology, 99(4), 700-714.

Funder, D. C., \& Ozer, D. J. (2019). Evaluating effect size in psychological research: Sense and nonsense. Advances in Methods and Practices in Psychological Science, 2(2), 156-168.

Galdiolo, S., \& Roskam, I. (2014). Development of personality traits in response to childbirth: A longitudinal dyadic perspective. Personality and Individual Differences, 69, 223-230.

Haase, C. M., Heckhausen, J., \& Wrosch, C. (2013). Developmental regulation across the life span: Toward a new synthesis. Developmental Psychology, 49(5), 964-972.

Heckhausen, J. (1999). Developmental goals as organizers of developmental regulation. In Developmental regulation in adulthood: Age-normative and sociostructural constraints as adaptive challenges (pp. 102-121). Cambridge University Press. https://doi.org/10.1017/ CBO9780511527852.006

Helbig, S., Lampert, T., Klose, M., \& Jacobi, F. (2006). Is parenthood associated with mental health? Social Psychiatry and Psychiatric Epidemiology, 41(11), 889-896.

Hennecke, M., \& Freund, A. M. (2017). The development of goals and motivation. In J. Specht (Ed.), Personality development across the lifespan (pp. 257-273). Academic Press Elsevier.

Hill, P. L., Jackson, J. J., Nagy, N., Nagy, G., Roberts, B. W., Lüdtke, O., \& Trautwein, U. (2016). Majoring in selection, and minoring in socialization: The role of the college experience in goal change post-high school. Journal of Personality, 84(2), 194-203.

Hopwood, C. J., \& Donnellan, M. B. (2010). How should the internal structure of personality inventories be evaluated? Personality and Social Psychology Review, 14(3), 332-346.

Hu, L.-t., \& Bentler, P. M. (1999). Cutoff criteria for fit indexes in covariance structure analysis: Conventional criteria versus new alternatives. Structural Equation Modeling, 6(1), 1-55.

Jokela, M., Alvergne, A., Pollet, T. V., \& Lummaa, V. (2011). Reproductive behavior and personality traits of the Five Factor Model. European Journal of Personality, 25(6), 487-500.

Lenhausen, M. R., Hopwood, C., van Scheppingen, M. A., \& Bleidorn, W. (2021). The prototypical parent personality [Manuscript submitted for publication].

Lenhausen, M. R., van Scheppingen, M. A., \& Bleidorn, W. (2020). Self-other agreement in personality development in romantic couples. European Journal of Personality. doi: $10.1177 / 0890207020969011$

Little, T. D., Cunningham, W. A., Shahar, G., \& Widaman, K. F. (2002). To parcel or not to parcel: Exploring the question, weighing the merits. Structural Equation Modeling, 9(2), 151-173.

Little, T. D., Rhemtulla, M., Gibson, K., \& Schoemann, A. M. (2013). Why the items versus parcels controversy needn't be one. Psychological Methods, 18(3), 285-300. https://doi.org/10.1037/a0033266 
Lüdtke, O., Trautwein, U., \& Husemann, N. (2009). Goal and personality trait development in a transitional period: Assessing change and stability in personality development. Personality and Social Psychology Bulletin, 35(4), 428-441.

Mckenzie, S. K., \& Carter, K. (2013). Does transition into parenthood lead to changes in mental health? Findings from three waves of a population based panel study. J Epidemiol Community Health, 67(4), 339-345.

Nelson, S. K., Kushlev, K., \& Lyubomirsky, S. (2014). The pains and pleasures of parenting: When, why, and how is parenthood associated with more or less well-being? Psychological Bulletin, 140(3), 846-896. https://doi.org/ 10.1037/a0035444

Nomaguchi, K. M., \& Bianchi, S. M. (2004). Exercise time: Gender differences in the effects of marriage, parenthood, and employment. Journal of Marriage and Family, 66(2), 413-430.

OECD. (2019). Part-time employment rate. https://data. oecd.org/emp/part-time-employment-rate.htm

Ozer, D. J., \& Gjerde, P. F. (1989). Patterns of personality consistency and change from childhood through adolescence. Journal of Personality, 57(2), 483-507.

Payne, E. C., Robbins, S. B., \& Dougherty, L. (1991). Goal directedness and older-adult adjustment. Journal of Counseling Psychology, 38(3), 302-308. https://doi.org/ 10.1037/0022-0167.38.3.302

Pickles, A., \& Rutter, M. (1991). Statistical and conceptual models of 'turning points' in developmental processes. In D. Magnusson, G. Rudinger, \& L. R. Bergman (Eds.), Problems and methods in longitudinal research: Stability and change (pp. 133-165). Cambridge University Press. https://doi.org/10.1017/CBO9780511663260.009

Pöhlmann, K., \& Brunstein, J. C. (1997). GOALS: Ein Fragebogen zur Messung von Lebenszielen. Diagnostica, 43(1), 63-79.

Pöhlmann, K., Brunstein, J. C., Koch, R., Brähler, E., \& Joraschky, P. (2010). Der Lebenszielfragebogen GOALS: Befunde zur internen und externen Validität auf der Basis einer repräsentativen Bevölkerungsstichprobe und einer klinischen Stichprobe. Zeitschrift für medizinische Psychologie, 19(2), 70-80.

Pollmann-Schult, M. (2014). Parenthood and life satisfaction: Why don't children make people happy? Journal of Marriage and Family, 76(2), 319-336.

Poudevigne, M. S., \& O'Connor, P. J. (2006). A review of physical activity patterns in pregnant women and their relationship to psychological health. Sports Medicine, 36(1), 19-38.

Putnick, D. L., \& Bornstein, M. H. (2016). Measurement invariance conventions and reporting: The state of the art and future directions for psychological research. Developmental Review, 41, 71-90. https://doi.org/10. 1016/j.dr.2016.06.004

R Core Team. (2020). R: A language and environment for statistical computing. https://www.R-project.org/

Roberts, B. W., O'Donnell, M., \& Robins, R. W. (2004). Goal and personality trait development in emerging adulthood. Journal of Personality and Social Psychology, 87(4), 541-550.
Roberts, B. W., \& Robins, R. W. (2000). Broad dispositions, broad aspirations: The intersection of personality traits and major life goals. Personality and Social Psychology Bulletin, 26(10), 1284-1296.

Roeters, A., Mandemakers, J. J., \& Voorpostel, M. (2016). Parenthood and well-being: The moderating role of leisure and paid work. European Journal of Population, 32(3), 381-401.

Rosseel, Y. (2012). lavaan: An R package for structural equation modeling. Journal of Statistical Software, 48(2), 1-36. http://www.jstatsoft.org/v48/i02/

Ruppanner, L., Perales, F., \& Baxter, J. (2019). Harried and unhealthy? Parenthood, time pressure, and mental health. Journal of Marriage and Family, 81(2), 308-326.

Salmela-Aro, K., Aunola, K., \& Nurmi, J.-E. (2007). Personal goals during emerging adulthood: A 10-year follow up. Journal of Adolescent Research, 22(6), 690-715.

Salmela-Aro, K., Nurmi, J.-E., Saisto, T., \& Halmesmäki, E. (2000). Women's and men's personal goals during the transition to parenthood. Journal of Family Psychology, 14(2), 171-186.

Salmela-Aro, K., Nurmi, J.-E., Saisto, T., \& Halmesmäki, E. (2010). Spousal support for personal goals and relationship satisfaction among women during the transition to parenthood. International Journal of Behavioral Development, 34(3), 229-237.

Sheldon, K. M., \& Cooper, M. L. (2008). Goal striving within agentic and communal roles: Separate but functionally similar pathways to enhanced well-being. Journal of Personality, 76(3), 415-448.

Specht, J., Egloff, B., \& Schmukle, S. C. (2011). Stability and change of personality across the life course: The impact of age and major life events on mean-level and rank-order stability of the Big Five. Journal of Personality and Social Psychology, 101(4), 862-882.

Stephenson, W. (1950). A statistical approach to typology: The study of trait-universes. Journal of Clinical Psychology, 6, 26-38.

Trucco, E. M., Wright, A. G., \& Colder, C. R. (2014). Stability and change of social goals in adolescence. Journal of Personality, 82(5), 379-389.

Umberson, D., Pudrovska, T., \& Reczek, C. (2010). Parenthood, childlessness, and well-being: A life course perspective. Journal of Marriage and Family, 72(3), 612-629.

van Scheppingen, M. A., Denissen, J. J., \& Bleidorn, W. (2018). Stability and change in self-control during the transition to parenthood. European Journal of Personality, 32(6), 690-704.

van Scheppingen, M. A., Jackson, J. J., Specht, J., Hutteman, R., Denissen, J. J., \& Bleidorn, W. (2016). Personality trait development during the transition to parenthood: A test of social investment theory. Social Psychological and Personality Science, 7(5), 452-462.

Zimmermann, J., Schubert, K., Bruder, M., \& Hagemeyer, B. (2017). Why go the extra mile? A longitudinal study on sojourn goals and their impact on sojourners' adaptation. International Journal of Psychology, 52(6), 425-435. 